\title{
Remote sensing and geochemistry techniques for the assessment of coal mining pollution, Emalahleni (Witbank), Mpumalanga.
}

\author{
Mafuza Maya ${ }^{1 *}$, Chiedza Musekiwa ${ }^{1}$, Ponani Mthembi ${ }^{1}$, Melissa Crowley ${ }^{1}$, \\ ${ }^{1}$ Council for Geoscience \\ *Corresponding author: Email: mmaya@geoscience.org.za
}

DOI: http://dx.doi.org/10.4314/sajg.v4i2.9

\begin{abstract}
Environmental degradation associated with coal mining is one of the serious environmental issues in South Africa that is expected to continue with increasing energy demands. Mapping and monitoring contamination in mining areas are necessary to guide rehabilitation activities. Rapid monitoring systems are needed to develop effective rehabilitation plans. The advent of multispectral remote sensing data has proven to be effective in mapping and detecting mine related soil contamination. An integrated approach of soil geochemistry and remotely sensed data to characterise contamination in Emalahleni coal fields is presented in this study. Aster data was acquired and several band combinations were developed to identify patterns and occurrence of soil contamination. For geochemical assessment, the Nemerow index and the pollution loading index were calculated to evaluate the mining activity contamination.

The classified aster images showed that contamination varies with land use. Residential areas and mining areas showed similar trends of contamination. Geochemical results showed that iron, vanadium and chromium are the most abundant elements in the study area. The findings of contamination indices reveal that the overall level of metal contamination in the study area is between moderate to heavily contaminated. The most polluted areas are concentrated in mining areas and along major transport intersections. The ASTER band ratios for silica and clay phases correspond with classified contamination indices indicating that remote sensing can successfully be used to assess pollution.
\end{abstract}




\section{Introduction}

Coal mining for electricity generation has been the main activity in the Mpumalanga Province from the 1870s. Approximately 22 Collieries surround the Emalahleni area and a steel mill, vanadium and ferrometal processing plants are also found. Emalahleni coal mining area supports 5 coal-fired power stations and forms part of national Eskom power grid. It is estimated that these power stations produces more than $25 \mathrm{Mt}$ of fly ash per annum (Eskom, 2014). A significant amount of ash material from coal power stations is disposed in landfill sites and about $5 \%$ of the generated ash is used as backfill material (Ayanda et al, 2012). The alkaline nature of the ash material makes it attractive alternative in treating acid mine drainage (Vadapilli et al, 2008). Since the ash material contains elevated concentrations of toxic metals, the ash can serve as the source of metals when not properly disposed.

Emalahleni coal field district has the worst air quality is the worst in the world because of power-stations burning coal, coal mining activities and uncontrollable ground fires. Department of Environmental Affairs declared this air pollution hotspot as Highveld Priority Area under the in terms of the National Environmental Management: Air Quality Act (39 of 2004) (Munnik, 2010). Air pollution in this area is characterised by high levels of sulphur dioxide, particulates, nitrogen dioxide, ozone, benzene and toluene (Pone et al, 2007). These gases range from 0.3 to 180 parts per billion (ppb) in the summer months and are much higher in winter because of thermal inversion. High levels of these pollutants have also been attributed to fuel combustion, vehicle emissions and domestic combustion of coal. Underground mining operations are old and subsidence of mining structure is a common feature in Emalahleni (Bell et al, 2001). Ground subsidence results in derelict and unusable land characterised by vents which as conduit for oxygen and spontaneous combustion (McCarthy and Pretorius, 2009; Munnik, 2010).

The impacts of air pollution on the surrounding soil in areas adjacent to mining operations have not been sufficiently investigated. A detailed background assessment of trace elements is needed to evaluate the impacts of mining. In particular, a determination of the variations of trace elements in terms of concentration and spatial distribution is necessary to understand the sources and the eventual sinks of trace elements. The spatial distribution of trace elements in the receiving soil in Emalahleni is often limited to the mining operations areas and therefore an assessment of contamination focussing on mining and industrial areas as well as the surrounding areas is needed. This requires cost effective technologies suitable for regional analysis that enable rapid assessment. Remote sensing is such a technique and its use, in combination with verification using geochemical data from field sampling, is very useful for assessing mining pollution. 
The goal of this research was to use geochemistry studies, pollution indices and ASTER remote sensing data to map heavy metal enrichment and accumulation near the Emalahleni coalfields. The study area is located in the mining area between Middleburg and Emalahleni in the eastern Highveld region and is characterised by grassland biomes. The climate of the region is highly seasonal with $85 \%$ of the mean annual precipitation of $690 \mathrm{~mm}$ falling in the growing season (October to March). Frost, often severe, occurs in winter. The extreme maximum temperature is $38.9^{\circ} \mathrm{C}$ and the extreme minimum $-13.3^{\circ} \mathrm{C}$ (SRK, 2009) . The topography of the area is relatively flat to strongly undulating to the northern parts (Figure 1).

The town still has a number of active coal mines operated by different coal mining companies, and more than 100 rundown and ownerless mines (as described in terms of Section 46 of the Minerals and Petroleum Resources Development Act No. 28 of 2002) (EO Miners, 2014).

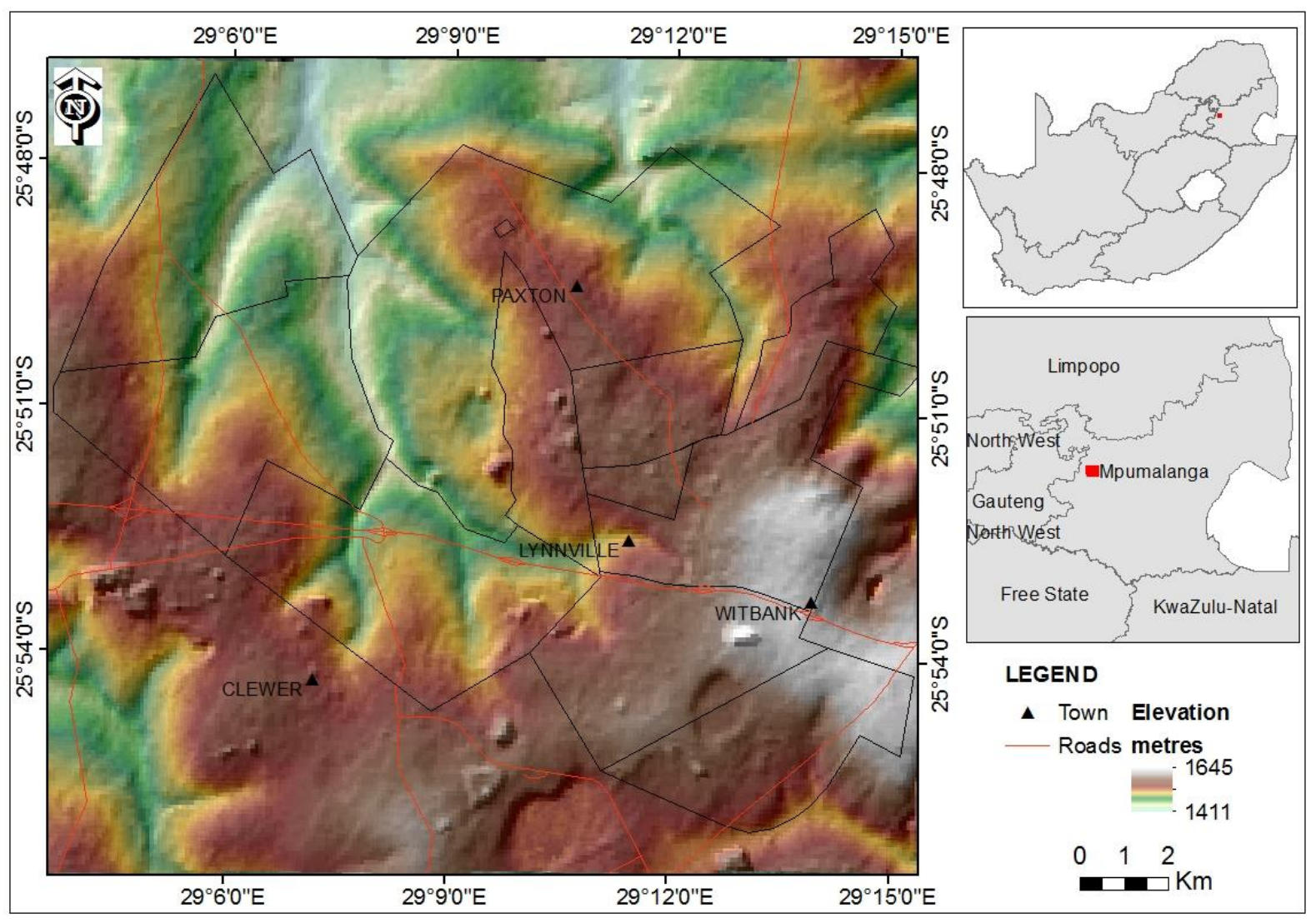

Figure 1. The location of the study area in the Mpumalanga Province in South Africa. 


\section{Methodology}

\subsection{Sampling and analysis}

Soil samples $(n=693)$ were collected from depths ranging from $0-20 \mathrm{~cm}$ in 2004 . Samples were taken at a $1 \mathrm{~km}^{2}$ interval. This is a sampling strategy of the regional geochemical mapping programme of South Africa. After sampling, soil samples were air dried and sieved through a $2 \mathrm{~mm}$ sieve. The samples were analysed on pressed powders by means of a simultaneous X-ray fluorescence spectrometer (S-XRF) according to the Council for Geoscience procedure described by Maritz et al. (2010). Additional samples $(\mathrm{n}=21)$ were taken in 2014 near mine tailings storage facilities and surrounding residential areas to determine the leachability of contaminated soils. These samples were taken at a depth of approximately $2-4 \mathrm{~cm}$ and were analysed by a wavelength dispersive X-ray fluorescence spectrometer (WD-XRF) on fused beads for major element analysis and pressed powder pellets for trace element analysis. Furthermore, these samples were analysed for electrical conductivity and hydrogen activity $(\mathrm{pH})$. Hyperspectral spectrum profiles for the samples were acquired from the 2014 data and were resampled to ASTER bands for image classification and analysis.

\subsection{Methods for metal pollution assessment}

Several methods were used to assess the quality of the soils in the area. First, the index of geoaccumulation (Igeo) was calculated from soil geochemical data. This index is used to evaluate heavy metal accumulation in sediments when compared to the background as it minimises the anthropogenic input of soil contaminants. According to Sutherland (2000), Igeo indices tend to reduce the contribution of parental rocks to the total concentration of heavy metals in soils. Igeo is calculated as follows (Equation 1):

$$
I_{\text {geo }}=\log _{2}\left(C_{n} / 1.5 \times B_{n}\right) \quad \text { Equation } 1
$$

Where $C_{n}$ is the measured concentration (in milligram per kilogram $(\mathrm{mg} / \mathrm{kg}$ )) of a specific element in the sample and $B_{n}$ is the geochemical background of the element. The factor 1.5 is introduced to accommodate the variation of background values attributable to terrigenous effects (Harikumar et al., 2010).

As the Igeo is a single element index, it does not provide a comprehensive state of contamination for the whole area and, in this, case the Newerow index was more suitable. The Newerow index $\left(\mathrm{I}_{\mathrm{N}}\right)$ is calculated from Igeo values to express the contribution of all metals in the area. The formula for the Nemerow index is: 


$$
\mathrm{I}_{\mathrm{N}}=\sqrt{ }\left(\mathrm{I}_{\text {geomax }}{ }^{2}+\mathrm{I}_{\text {geoave }}{ }^{2}\right) / 2 \quad \text { Equation } 2
$$

Where $\mathrm{I}_{\mathrm{N}}$ is the comprehensive contamination index of a sample, $\mathrm{I}_{\text {geomax }}$ is the maximum Igeo and $\mathrm{I}_{\text {geoave }}$ is the average value of Igeo.

The determination of the pollution load index commences with the calculation of the contamination factor (CF). The CF is used to quantify the level of contamination by a metal. The value is obtained by dividing the concentration of the individual metal by the background values of the metal. The pollution load index is used to determine the total contamination effect of the metals. This index is the geometric mean of the concentration of different trace metals present in the study area (Equation 3).

$$
P L I=\sqrt[n]{\text { Product of } n \text { number of CF values }}
$$

Equation 3

Where CF is the contamination factor and $\mathrm{n}$ is the number of metals. PLI values of less than 2 are classified as little or no pollution. PLI values of 4-8 indicate moderate to high pollution and PLI values above 32 represent extreme pollution. Using the results of $\mathrm{I}_{\mathrm{N}}$ and PLI indices, interpolation maps were constructed using Spatial Analyst in ArcMap. The inverse distance weighting method was selected as the interpolation method. The results are shown in Figure 2.

\section{Discussion of the results}

\subsection{Geochemical data analysis}

The concentrations of cobalt $(\mathrm{Co})$, chromium $(\mathrm{Cr})$, copper $(\mathrm{Cu})$, nickel $(\mathrm{Ni})$, lead $(\mathrm{Pb})$ and zinc $(\mathrm{Zn})$ in the soils of Emalahleni are presented in Table 1. In general, the concentrations of heavy metals vary greatly, which is typical of industrial soils. The average concentration of $\mathrm{Cr}, \mathrm{Ni}, \mathrm{Co}$ and vanadium (V) exceeded the South African permissible level values reported by Herselman (2007). Lead is the only element that showed a mean value lower than the permissible levels. Portion of high variation in concentration may be explained by the distribution of sampling sites as most samples were collected near mining areas. Based on concentration variation coefficient, heavy metals can be grouped into three classes: $\mathrm{As}$ and $\mathrm{Pb}$ with $\mathrm{CV}$ values lower than 20; $\mathrm{Co}, \mathrm{Ni}$ and $\mathrm{Cu}$ with $\mathrm{CV}$ values ranging from 20 to 100 and $\mathrm{Cr}$ 
and $\mathrm{V}$ with $\mathrm{CV}$ values more than 100. High CV values suggest anthropogenic influences while low CV suggests natural sources. Generally, the concentration results are comparable to other studies conducted in the area (SRK Report, 2013).

Table 1. Metal concentrations ( $\mathrm{mg} / \mathrm{kg}$ ) of soils in Emalahleni, South African permissible levels (mg/kg) from Herselman (2007), Coal and Fly Ash average concentrations (mg/kg) from Hlatshwayo (2008).

\begin{tabular}{cccccccc}
\hline Element & $\begin{array}{c}\text { Background } \\
\text { average }\end{array}$ & Average & Variation & $\begin{array}{c}\text { Soil } \\
\text { Permissible } \\
\text { levels }\end{array}$ & Coal & Fly Ash & Igeo \\
\hline $\mathrm{V}$ & 202 & 167 & 387 & 60 & 31 & 147 & 0.72 \\
$\mathrm{Cr}$ & 345 & 419 & 1053 & 26 & 43 & 265 & 1.43 \\
$\mathrm{Co}$ & 15 & 11 & 26 & 18 & 2 & 15 & -1.72 \\
$\mathrm{Ni}$ & 46 & 20 & 24 & 20 & 11 & 63 & 0.53 \\
$\mathrm{Cu}$ & 40 & 22 & 33 & 85 & 13 & 47 & -0.91 \\
$\mathrm{Zn}$ & 63 & 36 & 67 & 185 & 12 & 57 & -0.19 \\
$\mathrm{As}$ & 13 & 0.5 & 11 & 1.5 & 4 & 27 & 1.09 \\
$\mathrm{~Pb}$ & 13 & 19 & 19 & 81 & 14 & 149 & -0.33 \\
\hline
\end{tabular}

The geochemical maps of selected trace elements are shown in Figure 2. Distribution of As, $\mathrm{Cr}$ and $\mathrm{V}$ showed high values near mining areas. Coal power stations, mineral processing plant together with mine waste dumps are located in the study area. Dust in the area contains high levels of heavy metals and these metals maybe accumulated in soil through atmospheric deposition. Heavy traffic between the mines and coal stations is expected to be another source of $\mathrm{Pb}, \mathrm{Zn}$ and $\mathrm{Cu}$. Distribution maps show high concentration along secondary roads and at major traffic intersections. Several hotspots of high metal concentration can be clearly identified in geochemical maps. These hotspots are old mining sites that are converted informal residential areas.

The $\mathrm{pH}$ and electrical conductivity (EC) were measured to determine the oxidation potential of the soils and the distribution results are shown in Figure 3. The $\mathrm{pH}$ values range from 4.9 to 7.2 with an average of 5.9. Oxidation potential strongly affects the geochemical behaviour of metals in soil. The $\mathrm{pH}$ of leachate from half of the mine soil samples was more than 6, as shown in the cumulative plot in Figure 3, indicating near-neutral alkaline conditions. The high leachate $\mathrm{pH}$ indicates limited acidic run-off from these soils. 


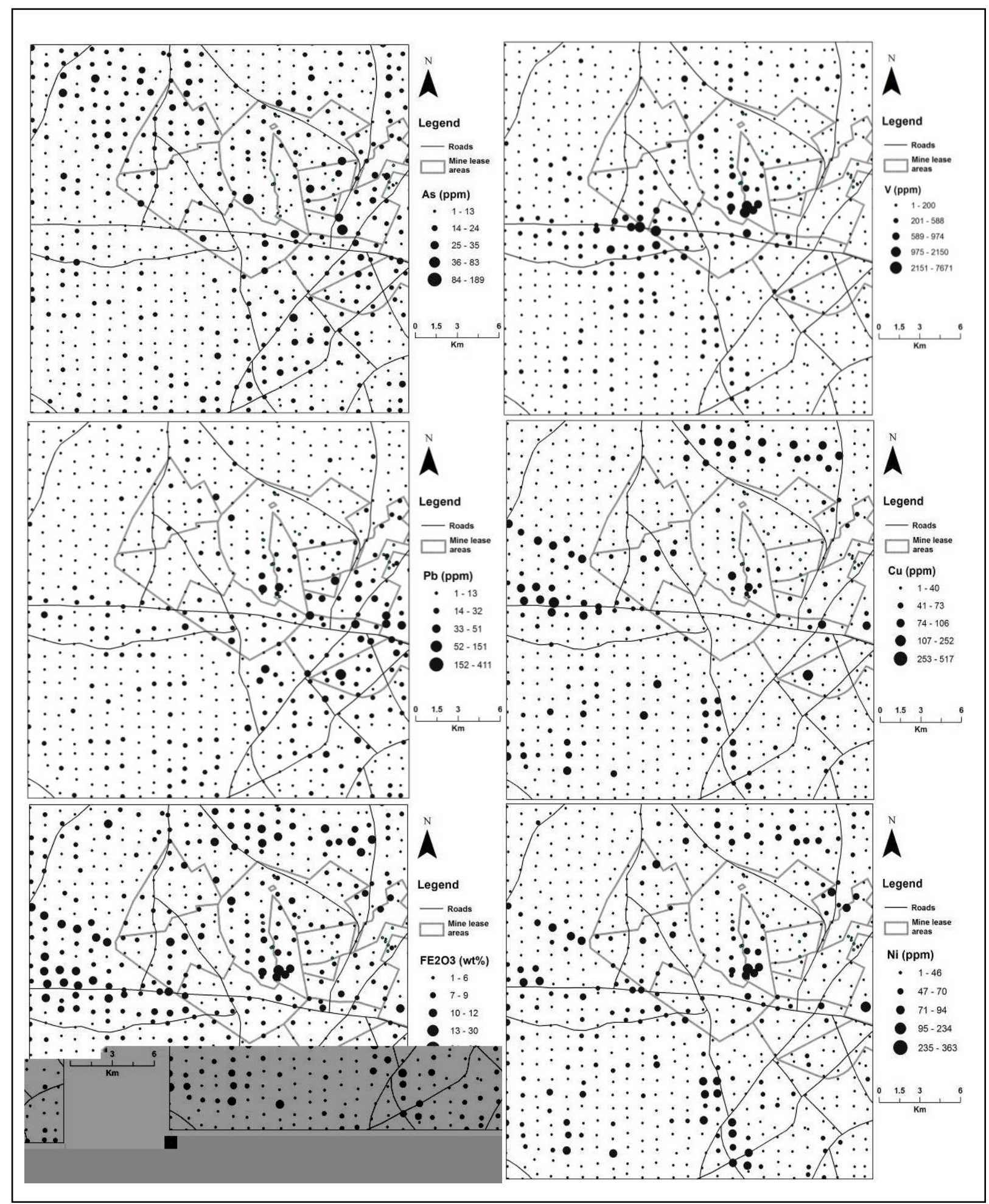

Figure 2. Geochemical maps of selected trace elements, $\mathrm{As}, \mathrm{V}, \mathrm{Pb}, \mathrm{Cu}, \mathrm{Ni}$, expressed in ppm and $\mathrm{FeO}$ wt $\%$ content. 


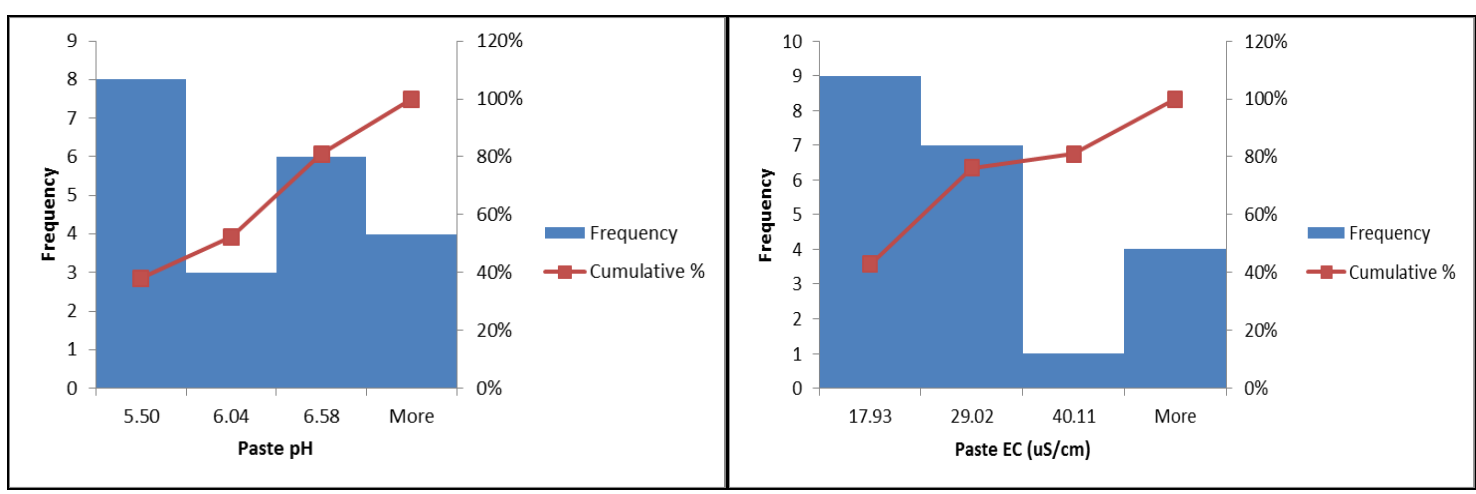

Figure 3. Histograms for the $\mathrm{pH}$ and $\mathrm{EC}$ of the samples.

A distribution plot of the paste EC results is shown in Figure 3. Electrical conductivity ranged from 7 to $51 \mu \mathrm{S} / \mathrm{cm}$ with the average mean of $22 \mu \mathrm{S} / \mathrm{cm}$. About $40 \%$ of the samples had paste EC values in excess of $40 \mu \mathrm{S} / \mathrm{cm}$. The low EC values in these soils can be attributed to limited organic matter content in samples that are dominated by sandy particles. Soluble salts measured as electrical conductivity shows great variation with distance from mine areas where EC was the highest near mine lease areas. The low EC results suggest small quantities of soluble salts present in the samples and the initial flushing on water quality should be small. These results can also be attributed to the alkaline nature of the coal fly ash described by Hlatshwayo (2008) and Vadapalli et al, 2008. The presence of alkalizing $\mathrm{CaCO}_{3}$ in the fly ash increases soil $\mathrm{pH}$ and improves physical properties of soils.

\subsection{Correlation analysis}

The relationships between heavy metals and major elements can provide important information on metal speciation and subsequent geochemical behaviour and this relationship can be used to elucidate metal sources and pathways. Pearson correlation coefficients of Emalahleni soils are summarised in Table 3 which shows a moderately positive correlation between $\mathrm{Cr}$, $\mathrm{Co}$, and $\mathrm{Pb}$. The contamination levels of these elements are relatively high. According to Sutherland (2000), this group of heavy metals can be associated with atmospheric deposition because $\mathrm{Cr}$ enters soils mainly through deposition and $\mathrm{Pb}$ and $\mathrm{Cu}$ are heavy metals that are always associated with anthropogenic sources, such as mining, welding, processing, and oil combustion. As the contamination levels of these heavy metals are high, they are likely to be emitted directly from coal mining activities.

The second group elements showing a significant positive correlation includes As, $\mathrm{Ni}$ and $\mathrm{Zn}$, which are commonly associated metals and which are generally detected in industrial areas. Given the low contamination levels of $\mathrm{Ni}, \mathrm{Zn}$ and $\mathrm{As}$, it can be assumed that industrial 
and mining areas are not the main contamination sources of this group. The correlation coefficients of the heavy metals $\mathrm{Cr}, \mathrm{Zn}$ and $\mathrm{Pb}$ with $\mathrm{Fe}_{2} \mathrm{O}_{3}$ were determined.

Table 3. Correlation matrix between trace and major elements $(p=0.05)$.

\begin{tabular}{|c|c|c|c|c|c|c|c|c|c|c|c|c|c|}
\hline & $\mathbf{A l}_{2} \mathbf{O}_{3}$ & $\mathrm{Fe}_{2} \mathrm{O}_{3}$ & MnO & $\mathrm{MgO}$ & $\mathrm{CaO}$ & As & Co & $\mathrm{Cr}$ & $\mathbf{C u}$ & $\mathbf{N i}$ & $\mathbf{P b}$ & $\mathbf{V}$ & $\mathbf{Z n}$ \\
\hline $\mathrm{Al}_{2} \mathrm{O}_{3}$ & 1 & 0.16 & -0.07 & 0.67 & 0.84 & 0.45 & -0.04 & 0.16 & 0.46 & 0.80 & 0.56 & -0.09 & 0.66 \\
\hline $\mathrm{Fe}_{2} \mathrm{O}_{3}$ & & 1 & 0.69 & 0.16 & -0.01 & 0.74 & 0.63 & 0.61 & 0.80 & 0.37 & 0.64 & 0.27 & 0.23 \\
\hline $\mathrm{MnO}$ & & & 1 & -0.10 & -0.12 & 0.27 & 0.93 & 0.58 & 0.77 & 0.11 & 0.56 & 0.27 & -0.11 \\
\hline $\mathrm{MgO}$ & & & & 1 & 0.67 & 0.33 & -0.05 & 0.01 & 0.30 & 0.81 & 0.48 & 0.34 & 0.81 \\
\hline $\mathrm{CaO}$ & & & & & 1 & 0.25 & -0.09 & 0.17 & 0.37 & 0.64 & 0.45 & -0.07 & 0.50 \\
\hline As & & & & & & 1 & 0.25 & 0.32 & 0.60 & 0.43 & 0.56 & -0.01 & 0.46 \\
\hline Co & & & & & & & 1 & 0.51 & 0.70 & 0.12 & 0.48 & 0.26 & -0.05 \\
\hline $\mathrm{Cr}$ & & & & & & & & 1 & 0.67 & 0.28 & 0.50 & 0.11 & 0.10 \\
\hline $\mathrm{Cu}$ & & & & & & & & & 1 & 0.54 & 0.82 & 0.25 & 0.26 \\
\hline $\mathrm{Ni}$ & & & & & & & & & & 1 & 0.54 & 0.40 & 0.82 \\
\hline $\mathrm{Pb}$ & & & & & & & & & & & 1 & 0.02 & 0.46 \\
\hline V & & & & & & & & & & & & 1 & 0.19 \\
\hline $\mathrm{Zn}$ & & & & & & & & & & & & & 1 \\
\hline
\end{tabular}

The correlation coefficient ( $r$ ) of $\mathrm{Cu}$ with $\mathrm{Fe}_{2} \mathrm{O}_{3}$ is 0.80 , and the $r$ values for $\mathrm{As}, \mathrm{Co}, \mathrm{Cr}$ and $\mathrm{Pb}$ with $\mathrm{Fe}_{2} \mathrm{O}_{3}$ are also $>0.6$. It is clear from these results that $\mathrm{Fe}_{2} \mathrm{O}_{3}$ plays an important role in adsorbing heavy metal elements in soil. The lack of correlation between $\mathrm{FeO}$ with $\mathrm{MnO}$ shows an oxidising environment with minimal sulphide oxidation. Minimal sulphide oxidation also indicates higher $\mathrm{pH}$ conditions which promote the precipitation of metals in clays.

\subsection{The improved Nemerow index}

To quantify the soil heavy metal contamination in the study area, the improved Nemerow index $\left(\mathrm{I}_{\mathrm{N}}\right)$, which describes the integrated contamination levels, was calculated as the sum of the eight heavy metals (Figure 5). Soil heavy metal enrichment and contamination in an area with a long mining history is large influenced by human activities. Atmospheric deposition, which results from prevailing wind direction changes, fossil fuel combustion, and irregular discharge of industrial sewage in the study area, are some of the reasons for the irregular distribution of heavy metal contamination in the soil. The calculated I-geo values in Table 1 show moderate soil contamination levels for $\mathrm{V}$, Ni and As and high soil contamination with $\mathrm{Cr}$. The $\mathrm{I}_{\mathrm{N}}$ results at all sampling points may be summarised as follows:

i) In general, the $\mathrm{I}_{\mathrm{N}}$ values are between 0.49 and 5.86. This finding reveals that the overall level of metal contamination in the study area is between heavily and extremely contaminated; 
ii) The $\mathrm{I}_{\mathrm{N}}$ values of more than ten sampling points exceed 5, which indicates that the contamination level is approaching extreme levels. The distribution of the sampling points with high $\mathrm{I}_{\mathrm{N}}$ values is similar to that of the metal pollution loading index.

iii) The uneven distribution of the contamination degree is another important feature of heavy metal contamination. As shown in Figure 5, the most polluted areas $\left(\mathrm{I}_{\mathrm{N}}>3.8\right)$ are concentrated in mining areas and along major transport intersections.

\subsection{Pollution load index}

As a complement to the study on integrated contamination levels, the risk of soil heavy metal contamination was quantified by calculating the pollution load index (ecological PLI), which describes the pollution risk level in the area (Figure 4). The PLI results reveal the following:

i) The PLI for all sampling points is from 0.2 to 4.6 , which shows an overall pollution risk level ranging from low to high. A large number of sampling points have values higher than 2, which indicates that the metal pollution risk level in a large portion of the area is moderate;

ii) The maximum PLI reaches 4.6 in residential areas. Figure 4 shows that a moderate pollution risk may also be observed along roads and at traffic intersections; and

iii) The PLI distribution shows the same trends as the $\mathrm{I}_{\mathrm{N}}$ results.

\subsection{ASTER imagery analysis}

band $5 x$ band 7

The results of ASTER clay mapping using band ratio: band $6 x$ band 6 and the $\mathrm{SiO}_{2}$ using band 12

band ratio band 13 were compared to the pollution model index and the sampling data (Figures 4 and 5). The results were successful and included the mapping of the heavily contaminated areas. These results were also verified using the locations of mine dumps. The ASD spectra were resampled to the ASTER data and compared to the USGS spectral library, with identification being carried out using Spectral Analyst in ENVI software. The results for most samples indicate likely matches to minerals in the silicate group such as zircon, zoisite and wollastonite which all contain high percentages of $\mathrm{SiO}_{2}$ in their composition. Mixture Tuned Matched Filtering (MTMF) classification was used to classify the ASTER data using ASD laboratory spectra. MTMF is an algorithm capable of determining the abundance of different end-members (minerals) within a pixel (ENVI, 2013). The results were successfully determined and are shown in Figure 6. Areas with high values are classified as close matches to the spectra from the samples. 


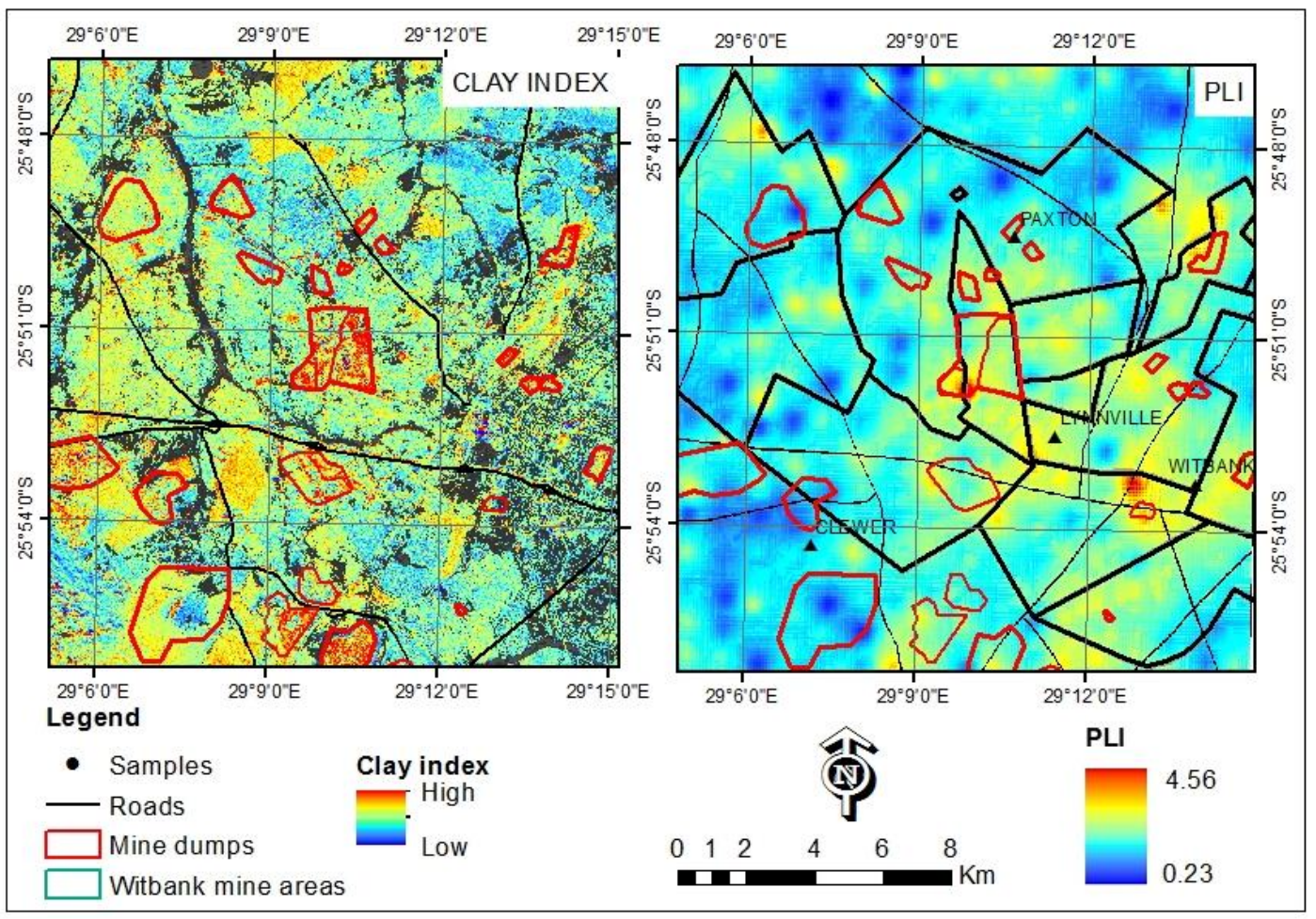

Figure 4. The ASTER clay mapping (with vegetation shown in black) compared to the PLI Index.

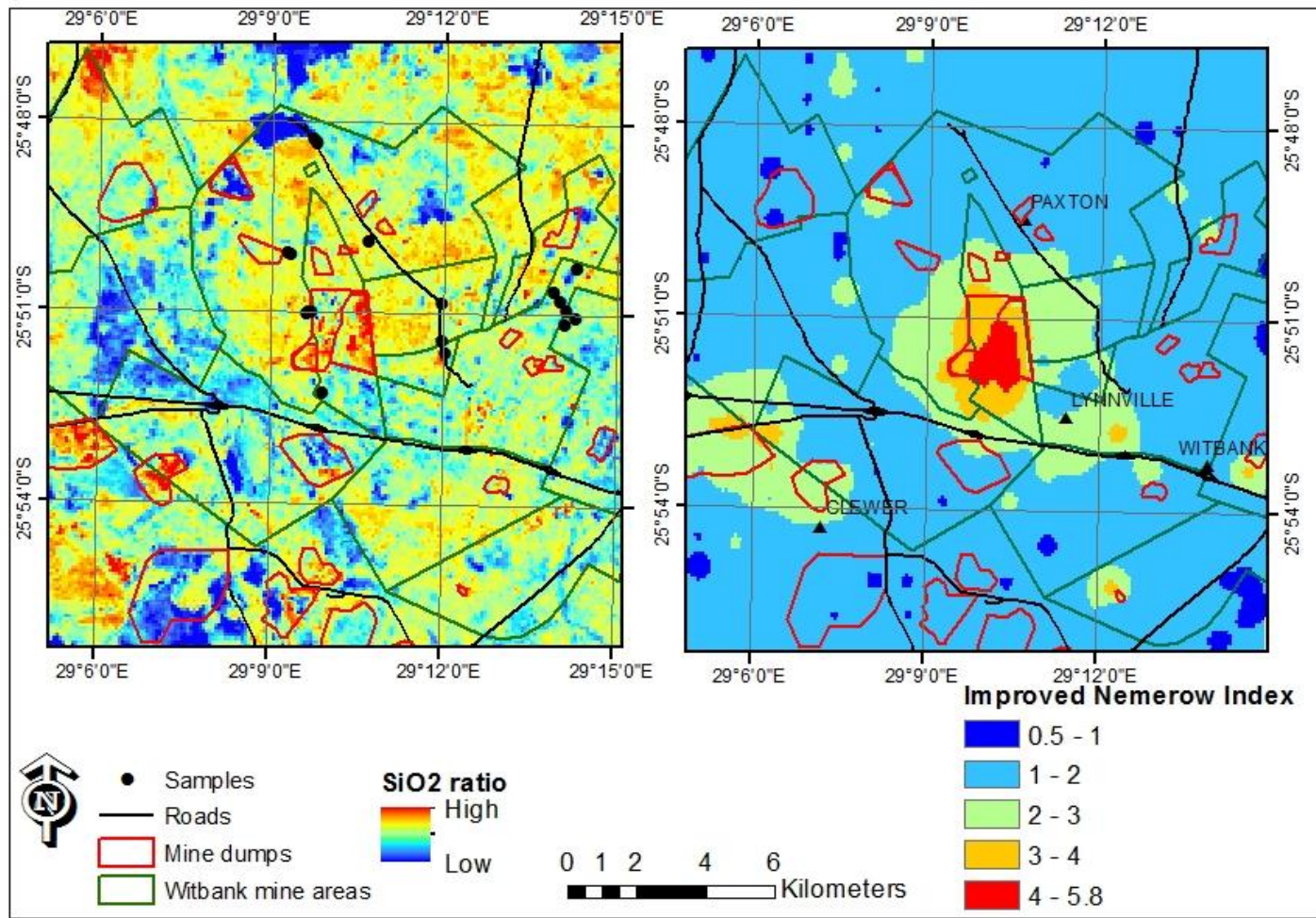

Figure 5. The results of $\mathrm{SiO}_{2}$ mapping from ASTER imagery (with vegetation shown in black) compared to the Nemerow index and the $\mathrm{SiO}_{2}$ from selected soil samples. 


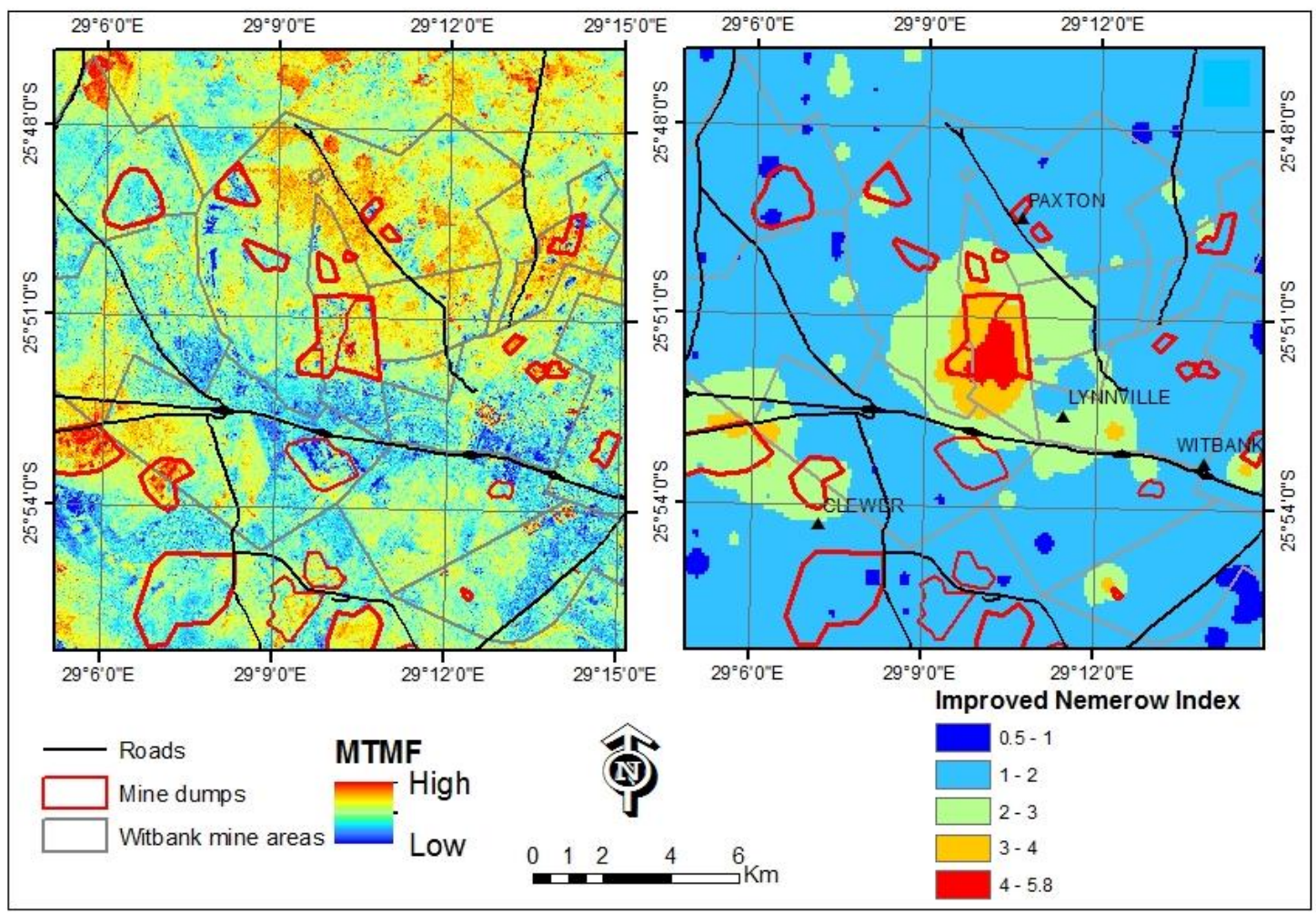

Figure 6. The MTMF classification compared to the $\mathrm{SiO}_{2}$ values and the Nemerow index.

\section{Conclusions and recommendations}

The high-density geochemical data allowed for the evaluation of metal enrichment in the soils of the coal mining area. The use of different assessment indices with spatial distribution facilitates better interpretations and comparison. Iron oxide $\left(\mathrm{Fe}_{2} \mathrm{O}_{3}\right)$ and silicon oxide $\left(\mathrm{SiO}_{2}\right)$ are the dominant major ions in the area. The study area is enriched in metals such as $\mathrm{Cr}, \mathrm{V}$, $\mathrm{Cu}, \mathrm{Ni}$ and As. This enrichment pattern is indicative of mining activities in the area. The contamination levels of the heavy metals are site specific. The results of the improved Nemerow index and the spatial interpolation maps indicate that the overall level of heavy metal contamination in the study area ranges from moderate to high. The geo-accumulation index (Igeo) and the integrated pollution load index (PLI) show an uneven distribution. PLI and Igeo results reflect the contamination from mining activities and from the transportation routes in the region. The PLI and Igeo contamination trends adjacent to mining areas are consistent with the common west-north to east-south winds, suggesting contamination by atmospheric deposition. The findings reveal that the overall levels of heavy metal contamination in the study area are between moderate to high. The distribution of the electrical conductivity and $\mathrm{pH}$ show that acidic conditions are also persistent in the residential soils. 
The ASTER mapping of $\mathrm{SiO}_{2}$ using the band ratio (Band 12 /Band 13) and the clay mapping using the band ratio: [(Band $5 \times$ Band 7) / (Band $6 \times$ Band 6)] corresponded with the sampling results, which indicated that remote sensing can be successfully used in pollution assessment. Visual analysis showed that the classification of ASTER using the ASD spectra and MTMF closely matched the pollution indices.

Recommendations for further studies include the use of hyperspectral data. Hyperspectral remote sensing data provide the ability to distinguish between spectrally similar minerals which is not possible using ASTER data only. The time-series assessment of vegetation stress is also crucial given that the heavy metal contamination has an effect on the health of vegetation in the area. The freely available Landsat and SPOT data may be useful in such studies.

\section{Acknowledgements}

The authors would like to acknowledge the Department of Science and Technology (DST) for funding this project. We would like to thank the Council for Geoscience for the resources and the time given to conduct this work. We would like to thank everyone at the CGS and the CSIR who was involved in the analyses of the soil samples. We also wish to thank Luncedo Ngcofe and Medhi Bensid for their contribution to the project.

\section{References}

Ayanda, O.S., Fatoki, O.S., Adekola, F.A., Ximba, B.J., 2012. Characterization of Fly Ash generated from Matla Power Station in Mpumalanga, South Africa. E-Journal of Chemistry 9(4) pp 17881795.

Bell, F.G., Bullock, S.E.T., Halbich, T.F.J., Lindsay, P. 2001. Environmental impacts associated with an abandoned mine in the Witbank Coalfield, South Africa. International Journal of Coal Geology 45 pp 195-216.

EO Miners. 2014. Earth observation to monitor mining impacts, <http://www.eominers.eu/earth observation/eo introduction.htm>. Accessed December 2014.

ENVI, 2013. Mixture Tuned Matched Filtering, <http://www.exelisvis.com/docs/MTMF.html>. Date Accessed: 10 November 2013. 
Eskom, 2014. Ash management in Eskom. (http://www.eskom.co.za/AboutElectricity/FactsFigures/Documents/CO_0004AshManagementRev 11.pdf) Date Accessed: 29 May 2014.

Harikumar, P. S, Nasir, U. P. and Mujeebu, R. M. P. (2009). Distribution of heavy metals in the core sediments of a tropical wetland system. Int. J. Environ. Sci. Tech., 6 (2) pp 225-232.

Herselman, J.E., 2007. The concentration of selected trace metals in South African soils. Ph.D. Thesis. University of Stellenbosch.

Hlatshwayo, T.B. (2008), The partition behavior and the chemical speciation of selected trace elements in a typical coal sample during pyrolysis. Msc Thesis: North-West University.

Kruse, F.A., Lefkoff, A.B., Boardman, J.B., Heidebrecht, K.B., Shapiro, A.T., Barloon, P.J. and Goetz, A.F.H. 1993. The Spectral Image Processing System (SIPS) - Interactive Visualization and Analysis of Imaging Spectrometer Data: Remote Sensing of Environment, Special issue on AVIRIS , vol. 44, pp. 145-163.

Maritz, H., Cloete, H.C.C. and Elsenbroek, J.H. 2010. Analysis of high density regional geochemical soil samples at the Council for Geoscience (South Africa): The importance of Quality Control measures. Geostandards and Geoanalytical Research, 34. pp 265-273.

McCarthy, T. S, and Pretorius, J.P. 2009. Coal mining on the Highveld and its implications for future water quality in the Vaal River system. In International Mine Water Conference. 19-23 October. Pretoria.

Munnik, V. 2010. The social and environmental consequence of coal mining in South Africa: A case study.http://www.bothends.org/uploaded_files/uploadlibraryitem/1case_study_South_Africa_updat ed.pdf. Date Accessed: 28 May 2015.

Pone, J.D.E., Hein, K.A.A., Stracher, G.B., Annegarn, H.J., Finkleman, B., Blake, R., McCormack, J.K., Schroeder, P. 2007. The spontaneous combustion of coal and its by-product in the Witbank and Sasol coalfields of South Africa. International Journal of Coal Geology 72, pp 124-140.

Sekabira, K., Oryem Origa, H., Basamba, A., Mutumba, G., Kakudidi, E. 2010. Assessment of heavy metal pollution in the urban stream sediments and its tributaries. Int. J. Environ. Sci. Tech 7(3) pp 435-446. 
SRK Report, 2009. Vlakfontein Coal Mine Environmental Impact Assessment: Soil Classification and Land Capability Specialist Report. Report No 400016/soils.

SRK Report, 2013. Draft Environmental Impact Assessment (EIA) for the Proposed Development of an Energy Recovery Plant at the Samancor Chrome Middelburg Ferrochrome Plant, Middelburg. SRK Project Number: 408836.

Sutherland, R.A. 2000. Bed sediment associated trace metals in an urban stream Oahu. Hawaii. Environmental Geology, vol. 39, pp. 611-627.

Vadapalli, V.R.K., Klink, M.J., Etchebers, O., Petrik, L.F., Gitari, W., White, R.A., Key, D., Iwuoha, E. 2008. Neutralization of acid mine drainage using fly ash, and strength development of the resulting solid residues. South African Journal of Science 104. 